\title{
eHealth Practices in Cancer Survivors With BMI in Overweight or Obese Categories: Latent Class Analysis Study
}

Annie Wen Lin ${ }^{1,2}$, BSc, MSc, PhD, RD; Sharon H Baik ${ }^{3,4}$, BSc, MSc, PhD; David Aaby ${ }^{2}$, BSc, MSc; Leslie Tello ${ }^{1}$; Twila Linville ${ }^{2}$, BSc, MSc; Nabil Alshurafa ${ }^{2}$, BSc, MSc, PhD; Bonnie Spring ${ }^{2}$, BA, MA, PhD

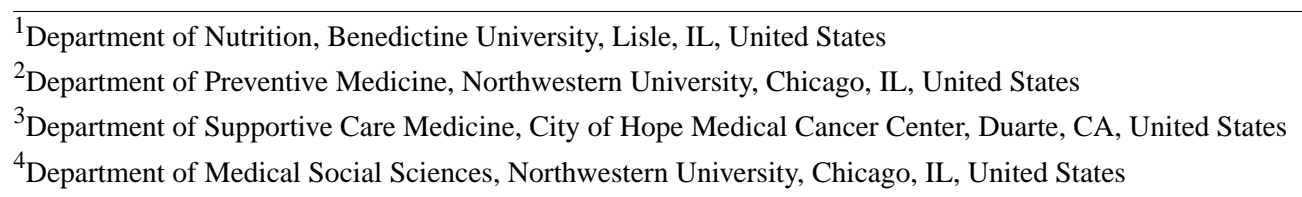

Corresponding Author:

Annie Wen Lin, BSc, MSc, PhD, RD

Department of Nutrition

Benedictine University

5700 College Road

Kindlon Hall, Room 224

Lisle, IL, 60532

United States

Phone: 16308291145

Email: alin@ben.edu

\section{Abstract}

Background: eHealth technologies have been found to facilitate health-promoting practices among cancer survivors with BMI in overweight or obese categories; however, little is known about their engagement with eHealth to promote weight management and facilitate patient-clinician communication.

Objective: The objective of this study was to determine whether eHealth use was associated with sociodemographic characteristics, as well as medical history and experiences (ie, patient-related factors) among cancer survivors with BMI in overweight or obese categories.

Methods: Data were analyzed from a nationally representative cross-sectional survey (National Cancer Institute's Health Information National Trends Survey). Latent class analysis was used to derive distinct classes among cancer survivors based on sociodemographic characteristics, medical attributes, and medical experiences. Logistic regression was used to examine whether class membership was associated with different eHealth practices.

Results: Three distinct classes of cancer survivors with BMI in overweight or obese categories emerged: younger with no comorbidities, younger with comorbidities, and older with comorbidities. Compared to the other classes, the younger with comorbidities class had the highest probability of identifying as female (73\%) and Hispanic (46\%) and feeling that clinicians did not address their concerns (75\%). The older with comorbidities class was 6.5 times more likely than the younger with comorbidities class to share eHealth data with a clinician (odds ratio [OR] 6.53, 95\% CI 1.08-39.43). In contrast, the younger with no comorbidities class had a higher likelihood of using a computer to look for health information (OR 1.93, 95\% CI 1.10-3.38), using an electronic device to track progress toward a health-related goal (OR 2.02, 95\% CI 1.08-3.79), and using the internet to watch health-related YouTube videos (OR 2.70, 95\% CI 1.52-4.81) than the older with comorbidities class.

Conclusions: Class membership was associated with different patterns of eHealth engagement, indicating the importance of tailored digital strategies for delivering effective care. Future eHealth weight loss interventions should investigate strategies to engage younger cancer survivors with comorbidities and address racial and ethnic disparities in eHealth use.

(JMIR Cancer 2020;6(2):e24137) doi: 10.2196/24137

\section{KEYWORDS}

eHealth; patient communication; cancer survivorship; obesity; behavior 


\section{Introduction}

More than 17 million cancer survivors reside in the United States, and simulation models predict that the survivorship population will increase to 22 million by January 2030 [1]. The growing prevalence of cancer survivors represents a significant health care challenge especially since they have higher risk for treatment-related morbidities (eg, cardiovascular disease) and cancer than the general population [2-4]. Obesity is considered a major risk factor for chronic disease, modifiable with energy-restricted, high-quality diets, and consistent physical activity [5]. Yet the prevalence of obesity continues to increase rapidly among cancer survivors [6] despite medical recommendations to maintain a healthy weight [7]. The prevalence of obesity among adult cancer survivors has increased $10 \%$ since 1997 , a significantly faster rate than among those without a history of cancer [6]. However, several issues restrict cancer survivors from accessing nutrition services, including inadequate reimbursement coverage, providers' heavy clinical load, and providers' limited nutrition or behavior change training $[8,9]$. To increase access to nutrition care, digital technology support for weight management and health promotion (eHealth) is being developed to facilitate healthy lifestyle change [10-12] and patient-clinician communication $[13,14]$.

Many eHealth interventions for cancer survivors, delivered through smartphone apps and internet websites, promote a high-quality diet and physical activity through behavior change techniques [15], such as goal-setting [16-21], self-monitoring of behavior [16-27], modeling of behavior [28], and behavioral feedback [16-19,21,24,26,28,29]. eHealth interventions have shown some promise for assisting cancer survivors with health-promoting behavior change and weight loss $[30,31]$ yet the one size fits all approach is unlikely to be effective for this population [32]. Individuals in the increasingly culturally and linguistically diverse survivor population may have different medical experiences, as well as different digital access and engagement [33]. The few studies [34-37] that have investigated associations among eHealth use, sociodemographic characteristics, and medical history examined the general population rather than cancer survivors. In these studies [34-37], researchers found poorer engagement in eHealth practices among adults who are older, male, in a lower annual income bracket, less healthy, or without a regular provider. Even less is known about how different care experiences are associated with different types of eHealth practices. However, a recent study [38] found that negative medical experiences (ie, low perceived patient-centeredness) were associated with greater engagement in self-management eHealth practices only among those with less education and not among those with more education, suggesting that eHealth use can vary as a function of sociodemographic factors and medical experiences. Further investigation is warranted to understand how and why different combinations of these factors are associated with varied eHealth practices among cancer survivors with BMI in overweight or obese categories. Latent class analysis is a statistical approach that allows an investigation of how the intersection of several patient-related factors are associated with eHealth use. This type of analysis is useful when there are several variables that can contribute to heterogeneity, such as that observed among cancer survivors and can facilitate understanding to guide optimization of eHealth promotion among different underlying cancer survivor subgroups.

The primary objective of the study was to determine whether distinct classes can be identified based on sociodemographic characteristics, medical history, and medical experiences (eg, patient-related factors) of cancer survivors with BMI in overweight or obese categories. We also investigated whether class membership was associated with eHealth practices for weight management and patient-clinician communication among cancer survivors with BMI in overweight or obese categories.

\section{Methods}

\section{National Cancer Institute Health Information National Trends Survey}

National Cancer Institute's Health Information National Trends Survey (NCI HINTS) is an ongoing cross-sectional data collection program for nationally representative data about health- and cancer-related communication in the United States. Details regarding the NCI HINTS sampling framework have been previously published [39]. During 2017-2018, self-administered questionnaires from NCI HINTS 5 Cycles 1 and 2 were mailed to households (address-based sampling). Surveys were deemed ineligible if $\leq 49 \%$ of the first 2 sections of the questionnaire were completed. The NCI HINTS 5 Cycles 1 and 2 comprised 6862 participants who returned their questionnaires to investigators, with a final collective response rate of $25 \%$. Of these questionnaires, 6789 (99\%) were considered completed by study investigators. In our study, participant data were excluded if respondents did not have a cancer history $(\mathrm{n}=3735)$ and had a BMI $<25 \mathrm{~kg} / \mathrm{m}^{2}(\mathrm{n}=2324)$.

\section{Variables}

All variables were categorical and were collected in NCI HINTS 5 Cycles 1 and 2. Sociodemographic variables included age, gender, race/ethnicity, and education level. Also included in the analysis were degree of weight above a healthy weight (overweight, class I obesity; class II obesity; class III obesity [40]), presence of medical conditions (diabetes, cardiovascular disease, or depression; hypertension; arthritis), frequency of medical visits in the past year, quality of care, health insurance status, access to medical records, and access to a regular provider. Medical experience characteristics included whether patients felt that (1) their feelings and emotions were addressed by clinicians, (2) they were involved in medical decisions, (3) their clinicians made certain that they understood next steps of care, (4) they received clear explanations from their clinicians, and (5) they were confident in their ability to take care of their own health. Response options for each medical experience questionnaire item were dichotomous (yes or no).

Nine eHealth items (outcome variables) were available across both cycles: access to a health app (1 item); use of electronic means to seek personal medical information ( 2 items), use of tablets or smartphones to track health and facilitate medical discussions (4 items), and use of the internet as a health resource 
( 2 items). Response options for these items were dichotomous (yes or no). Since deidentified data were available for public use from the National Cancer Institute, ethical approval was not required for this secondary data analysis.

\section{Statistical Analysis}

All analyses were conducted using STATA statistical software (version 15; StataCorp LLC). We used latent class analysis to empirically identify classes for cancer survivors with BMI in overweight or obese categories who exhibited similar sociodemographic and psychosocial characteristics [41]. The latent class model included sampling weights to account for the study design and to generate estimates and make inferences that reflect the population. The number of classes was selected using the Akaike information criterion (AIC); Schwarz Bayesian information criterion (BIC); Rissanen sample-size adjusted BIC; entropy, with higher values indicating better classification of individuals; and ease of interpretation (ie, the classes distinguished differences from a practical perspective). We examined a series of models, progressing from a 1-class model to a 10-class model, and compared the models using AIC, adjusted BIC, and entropy descriptive fit indices (Table 1) to identify the optimal number of classes $[42,43]$.

Table 1. Latent class model selection diagnostics.

\begin{tabular}{|c|c|c|c|c|c|}
\hline Classes, $\mathrm{n}$ & $\mathrm{G}^{2}$ deviance statistic & $\mathrm{AIC}^{\mathrm{a}}$ & $\mathrm{BIC}^{\mathrm{b}}$ & Adjusted $^{\mathrm{c}} \mathrm{BIC}$ & Entropy \\
\hline 1 & 7815.99 & 7879.99 & 8026.96 & 7925.35 & 1.00 \\
\hline 2 & 7424.36 & 7554.36 & 7852.91 & 7646.52 & 0.56 \\
\hline 3 & 7074.80 & 7270.80 & 7720.92 & 7409.73 & 0.74 \\
\hline 4 & 6930.33 & 7192.33 & 7794.02 & 7378.05 & 0.77 \\
\hline 5 & 6845.61 & 7173.61 & 7926.87 & 7406.12 & 0.74 \\
\hline 6 & 6648.00 & 7042.00 & 7946.83 & 7321.30 & 0.77 \\
\hline 7 & 6574.32 & 7034.32 & 8090.72 & 7360.40 & 0.82 \\
\hline 8 & 6447.51 & 6973.51 & 8181.48 & 7346.37 & 0.82 \\
\hline 9 & 6300.65 & 6892.65 & 8252.19 & 7312.29 & 0.83 \\
\hline 10 & 6238.49 & 6896.49 & 8407.60 & 7362.92 & 0.83 \\
\hline
\end{tabular}

${ }^{\mathrm{a}} \mathrm{AIC}$ : Akaike information criterion.

${ }^{b}$ BIC: Bayesian information criterion.

${ }^{\mathrm{c}}$ Rissanen sample size adjustment.

We determined that the 3-class model was optimal (AIC 7270.80; adjusted BIC 7409.73; entropy 0.74). Specifically, all indicators of model fit (decreased AIC and adjusted BIC, higher entropy) revealed the 2-class model fit better than the 1-class model, and the 3-class model fit better than the 2-class model. Although the slightly lower AIC and adjusted BIC values, and slightly higher entropy indicated the 4-class model fit better than the 3-class model, the 3-class model demonstrated both (1) a relatively larger decrease in the AIC and adjusted BIC values (2-class to 3-class compared to 3-class to 4-class) and (2) and a similar entropy ( 0.74 in 3 -class vs 0.77 in 4 -class). Also, the 4-class model seemed to separate Class 1 from the 3-class model into 2 distinct classes; however, these classes did not differ in any meaningful or interpretable way. The 3-class model provided the most clinically interpretable groups.

Maximum conditional probabilities for the categorical indicator variables (ie, sociodemographic, medical, and psychosocial factors) were used to characterize each class. Variables with probabilities greater than 0.50 were highly endorsed [44]. We used logistic regression to examine whether latent class membership was associated with different eHealth behaviors. Each eHealth behavior was modeled separately, using the latent classes as predictors in the model. We evaluated differences between classes using the pseudo class method, with 20

imputations. The pseudo-class method [45] provides conservative estimates of standard error and perform optimally for models with moderate entropy (0.60) and competitively for models with large entropy (0.80). Logistic regression analyses did not adjust for covariates since classes were derived from sociodemographic factors, medical history, and medical experiences, and thus their covariance was already incorporated into the analysis. We present odds ratios (ORs) and 95\% confidence intervals from the logistic regression models.

\section{Results}

\section{Sample Characteristics}

The sample of cancer survivors with BMI in overweight or obese categories $(\mathrm{N}=730)$ had a mean age of 66.8 (SD 11.9) years, and these participants were mostly non-Hispanic White individuals (499/730, 76.3\%) (Table 2). There was a slightly higher proportion of females $(396 / 730,55.1 \%)$ than males $(323 / 730,44.9 \%)$. Most had a BMI considered overweight $(383 / 730,52.5 \%)$, had health insurance $(694 / 730,97.3 \%)$, and a regular health care provider $(624 / 730,86.4 \%)$. Approximately half of the participants had been offered online access to medical records $(313 / 730,51.4 \%)$. Overall, for all 3 classes, participants had nearly equal probability of being offered online access to medical records (range 43\%-54\%). 
Table 2. Demographic characteristics of the sample $(\mathrm{N}=730)$.

\begin{tabular}{|c|c|}
\hline Characteristic & Value, $\mathrm{n}(\%)$ \\
\hline \multicolumn{2}{|l|}{ Age } \\
\hline Less than 49 years & $58(8.1)$ \\
\hline $50-64$ years & $226(31.7)$ \\
\hline $65-74$ years & $250(35.1)$ \\
\hline 75 years or older & $178(25.0)$ \\
\hline \multicolumn{2}{|l|}{ Gender } \\
\hline Male & $323(44.9)$ \\
\hline Female & $396(55.1)$ \\
\hline \multicolumn{2}{|l|}{ Race/ethnicity } \\
\hline Non-Hispanic White & $499(76.3)$ \\
\hline Black or African American & $78(11.9)$ \\
\hline Hispanic & $54(8.3)$ \\
\hline Hawaiian/Pacific Islander, Alaskan Native, Asian, or Multiracial ${ }^{\mathrm{a}}$ & $23(3.5)$ \\
\hline \multicolumn{2}{|l|}{ Education } \\
\hline High School or less & $202(28.2)$ \\
\hline Some college, professional school & $239(33.4)$ \\
\hline College graduate & $275(38.4)$ \\
\hline \multicolumn{2}{|l|}{ BMI category $[40]$} \\
\hline Overweight & $383(52.5)$ \\
\hline Obese, class I & $214(29.3)$ \\
\hline Obese, class II & $75(10.3)$ \\
\hline Obese, class III & $58(7.9)$ \\
\hline \multicolumn{2}{|l|}{ Diabetes, heart condition, or depression } \\
\hline Present & $405(57.0)$ \\
\hline Absent & $306(43.0)$ \\
\hline \multicolumn{2}{|l|}{ Hypertension } \\
\hline Present & $449(62.3)$ \\
\hline Absent & $272(37.7)$ \\
\hline \multicolumn{2}{|l|}{ Arthritis } \\
\hline Present & $351(48.5)$ \\
\hline Absent & $373(51.5)$ \\
\hline \multicolumn{2}{|c|}{ How many times did you go to a health professional (doctor, nurse) for care } \\
\hline None & $39(5.4)$ \\
\hline $1-3$ times & $292(40.6)$ \\
\hline $4+$ times & $388(54.0)$ \\
\hline \multicolumn{2}{|l|}{ Quality of care } \\
\hline Excellent & $300(44.8)$ \\
\hline Very good & $231(34.5)$ \\
\hline Good & $112(16.7)$ \\
\hline Fair & $23(3.4)$ \\
\hline Poor & $3(0.4)$ \\
\hline Health insurance & \\
\hline
\end{tabular}




\begin{tabular}{|c|c|}
\hline Characteristic & Value, $\mathrm{n}(\%)$ \\
\hline Yes & $694(97.3)$ \\
\hline No & $19(2.7)$ \\
\hline \multicolumn{2}{|c|}{ Offered online access to your medical records } \\
\hline Yes & $313(51.4)$ \\
\hline No & $296(48.6)$ \\
\hline \multicolumn{2}{|c|}{ Confidence in own ability to take care of health } \\
\hline Completely confident & $7(1.0)$ \\
\hline Very confident & $30(4.1)$ \\
\hline Somewhat confident & $189(26.1)$ \\
\hline A little confident & $345(47.7)$ \\
\hline Not confident at all & $153(21.1)$ \\
\hline \multicolumn{2}{|l|}{ Regular provider } \\
\hline Yes & $624(86.4)$ \\
\hline No & $98(13.6)$ \\
\hline \multicolumn{2}{|l|}{ Feelings addressed } \\
\hline Yes & $642(95.8)$ \\
\hline No & $28(4.2)$ \\
\hline \multicolumn{2}{|l|}{ Involved in decisions } \\
\hline Yes & $660(97.9)$ \\
\hline No & $14(2.1)$ \\
\hline \multicolumn{2}{|l|}{ Understood next steps } \\
\hline Yes & $666(99.1)$ \\
\hline No & $6(0.9)$ \\
\hline \multicolumn{2}{|l|}{ Explained clearly } \\
\hline Yes & $668(99.3)$ \\
\hline No & $5(0.7)$ \\
\hline
\end{tabular}

${ }^{\mathrm{a}}$ These data were grouped for statistical analysis (due to the very small number of participants and model fit).

Multimedia Appendix 1 shows the percentage of participants within each class and the resulting conditional response probabilities of endorsing items, given class membership.

\section{Classes}

Class 1 accounted for $41 \%$ of the population (Multimedia Appendix 1). The majority of class 1 was less than 65 years old (77\%), had higher than high school education level (80\%), and identified as being non-Hispanic White individuals (80\%). In this class, there was a higher probability of having a BMI in overweight and obese class I categories $(91 \%)$ and a lower probability of having medical conditions-diabetes, cardiovascular disease, or depression; hypertension; arthritis - than in the other classes (range 9\%-31\%). Members in class 1 predominantly had health insurance $(98 \%)$, visited a regular provider $(82 \%)$, and felt little to somewhat confident in their ability to take care of their own health $(73 \%)$. Most reported having positive interactions with their clinicians: they believed that their feelings were addressed (95\%), felt involved in decisions (100\%), understood next steps in care (100\%), and felt that health-related topics were clearly explained (100\%). Class 1 was subsequently labeled younger with no comorbidities.

Class 2 represented the smallest class accounting for $4 \%$ of the population. A slight majority of its members were less than 64 years old (57\%; Multimedia Appendix 1). Compared to the other classes, class 2 had the highest probability of identifying as female $(73 \%)$ and having a high school education level or less $(60 \%)$. The probability of class members identifying as Black or Hispanic adults $(63 \%)$ was substantially higher than in classes $1(17 \%)$ and $3(16 \%)$. Class 2 had the highest probability of having a BMI in obese class II and III categories $(63 \%)$ and having medical conditions (\% range: $48-95 \%$ ), and probabilities for this class of seeking care from a health care professional (31\%), having a regular provider (43\%), and having health insurance $(24 \%)$ were lower than for other classes. Class 2 had a higher probability of reporting low quality of care (37\%) than the other classes; they were more likely to believe their feelings were not addressed by health care professionals $(75 \%)$ and to feel uninvolved in decisions (73\%). Yet there was a high probability of feeling — at a minimum—very confident in their 
ability to take care of their own health (56\%). Class 2 was subsequently labeled younger with comorbidities.

Class 3 represented the largest class and accounted for $55 \%$ of the population (Multimedia Appendix 1). The majority of class 3 was 65 years old or above $(71 \%)$, identified as non-Hispanic White individuals (83\%), and had a BMI within either overweight or obese class I categories $(81 \%)$. There was an even distribution regarding education level among its members. Members of class 3 predominantly had health insurance $(99 \%)$, had a regular provider (90\%), expressed feeling a little to somewhat confident in their ability to take care of health (77\%), and reported positive interactions with their clinicians, similar to class 1 . Specifically, members in class 3 felt that in medical care, their feelings were addressed (97\%), they were involved in decisions (99\%), understood the next steps in care (100\%), and felt that things were explained clearly $(100 \%)$. There were differences in medical outcomes between classes 1 and 3, with class 3 having higher probabilities of being diagnosed with all comorbidities - diabetes, cardiovascular disease, or depression; hypertension; arthritis except for obesity (range 64\%-80\% vs
9\%-31\%). Class 3 was subsequently labeled older with comorbidities.

\section{Association of eHealth Behaviors and Latent Classes}

Table 3 presents the associations of eHealth behaviors with latent classes. Logistic regression analyses indicated that, compared with the younger with comorbidities class, the older with comorbidities class had more than a 6-fold increase in the odds of sharing health information from an electronic device or smartphone with a health professional (OR 6.53, 95\% CI 1.08-39.43). There were no significant differences in the likelihood of engaging in eHealth behaviors between younger with no comorbidities and younger with comorbidities classes (Table 3). The younger with no comorbidities class had greater odds than the older with comorbidities class of engaging in self-management eHealth practices that do not involve a health care provider, including using a computer to look for health information (OR 1.93, 95\% CI 1.10-3.38), using a tablet or smartphone to track progress toward a health-related goal (OR $2.02,95 \%$ CI 1.08-3.79), and using the internet to watch health-related videos on YouTube (OR 2.70, 95\% CI 1.52-4.81) (Table 3).

Table 3. Logistic regression models predicting eHealth behaviors using latent classes as predictors.

\begin{tabular}{|c|c|c|c|c|c|c|}
\hline \multirow[t]{2}{*}{ eHealth Behaviors } & \multicolumn{2}{|c|}{$\begin{array}{l}\text { Younger with no comorbidities } \\
\text { vs younger with comorbidities }\end{array}$} & \multicolumn{2}{|c|}{$\begin{array}{l}\text { Younger with no comorbidities } \\
\text { vs older with comorbidities }\end{array}$} & \multicolumn{2}{|c|}{$\begin{array}{l}\text { Older with comorbidities vs } \\
\text { younger with comorbidities }\end{array}$} \\
\hline & Odds ratio & $95 \% \mathrm{CI}$ & Odds ratio & $95 \% \mathrm{CI}$ & Odds ratio & $95 \% \mathrm{CI}$ \\
\hline $\begin{array}{l}\text { On your tablet or smartphone, do you have any } \\
\text { apps related to health and wellness? }\end{array}$ & 1.28 & $(0.29,5.58)$ & 1.61 & $(0.87,2.96)$ & 0.80 & $(0.18,3.63)$ \\
\hline $\begin{array}{l}\text { In the past } 12 \text { months have you used a computer, } \\
\text { smart phone, or other electronic means to look for } \\
\text { health or medical information for yourself? }\end{array}$ & 2.73 & $(0.73,10.14)$ & 1.93 & $(1.10,3.38)$ & 1.41 & $(0.39,5.11)$ \\
\hline $\begin{array}{l}\text { In the past } 12 \text { months have you used a computer, } \\
\text { smart phone, or other electronic means to look up } \\
\text { medical test results? }\end{array}$ & 2.16 & $(0.55,8.48)$ & 1.63 & $(0.99,2.67)$ & 1.33 & $(0.34,5.14)$ \\
\hline $\begin{array}{l}\text { Has your tablet or smartphone helped you track } \\
\text { progress on a health-related goal, such as quitting } \\
\text { smoking, losing weight, or increasing physical } \\
\text { activity? }\end{array}$ & 2.28 & $(0.47,11.02)$ & 2.02 & $(1.08,3.79)$ & 1.13 & $(0.23,5.46)$ \\
\hline $\begin{array}{l}\text { Has your tablet or smartphone helped you make } \\
\text { a decision about how to treat an illness or condi- } \\
\text { tion? }\end{array}$ & 1.25 & $(0.24,6.42)$ & 1.16 & $(0.63,2.15)$ & 1.08 & $(0.20,5.71)$ \\
\hline $\begin{array}{l}\text { Has your tablet or smartphone helped you in dis- } \\
\text { cussions with your health care provider? }\end{array}$ & 1.33 & $(0.22,7.85)$ & 0.67 & $(0.37,1.23)$ & 1.97 & $(0.31,12.50)$ \\
\hline $\begin{array}{l}\text { Have you shared health information from either } \\
\text { an electronic monitoring device or smartphone } \\
\text { with a health professional within the last } 12 \\
\text { months? }\end{array}$ & 3.63 & $(0.57,23.22)$ & 0.56 & $(0.27,1.13)$ & 6.53 & $(1.08,39.43)$ \\
\hline $\begin{array}{l}\text { In the last } 12 \text { months, have you used the internet } \\
\text { to participate in an online forum or support group } \\
\text { for people with a similar health or medical issue? }\end{array}$ & 2.11 & $(0.12,37.70)$ & 2.50 & $(0.68,9.16)$ & 1.40 & $(0.12,16.19)$ \\
\hline $\begin{array}{l}\text { In the last } 12 \text { months, have you used the internet } \\
\text { to watch a health-related video on YouTube? }\end{array}$ & 1.84 & $(0.42,8.11)$ & 2.70 & $(1.52,4.81)$ & 0.68 & $(0.15,2.99)$ \\
\hline
\end{tabular}

${ }^{\mathrm{a}}$ This class was used as the reference. 


\section{Discussion}

Despite the substantial investment in advancing eHealth to extend patient care [46], there is insufficient evidence about how sociodemographic factors, medical history, and medical experiences affect how different groups of cancer survivors use eHealth. As obesity is both prevalent and a significant risk factor for future multimorbidity among cancer survivors, our study objective was to characterize patterns of eHealth use among distinct classes of cancer survivors with BMI in overweight or obese categories. Three classes emerged: younger with no comorbidities; younger with comorbidities; older with comorbidities. People in the older with comorbidities class were less likely to use eHealth self-management technologies than those in the younger-no comorbidities class. However, when compared to those in the younger with comorbidities class, people in the older with comorbidities class were more likely to share health information from an eHealth device with a health professional.

Among cancer survivors with comorbidities, older adults were more likely than younger adults to share their eHealth data with a health care provider in order to facilitate patient-clinician communication. Our finding supports the supposition that eHealth is a promising tool to facilitate patient-clinician communication for older cancer survivors with comorbidities. In comparison, those in the younger with comorbidities class were less likely to have a regular provider, have health insurance, feel involved in medical decisions, or feel they understood next steps of care. They were also more likely to identify as Black or Hispanic individuals and have a lower education level. The characteristics observed in the younger with comorbidities class were consistent with previous reports that Black and Hispanic participants receive less health care than non-Hispanic White participants, and that cancer survivors with lower education are less likely to discuss health-promoting behaviors [47-49]. We also observed that the younger with comorbidities class did not emerge within the 2-class model. This observation suggests that minority groups among cancer survivors with BMI in overweight or obese categories can easily go unnoticed and underrepresented in health care despite having different medical experiences and being at increased risk of having a medical condition, relative to non-Hispanic White adults. A valuable opportunity exists for clinicians and researchers to identify strategies that will improve the medical experiences of underserved minority groups, while leveraging eHealth technology to facilitate health-promoting behaviors.

Compared to those in the older with comorbidities class, cancer survivors in the younger with no comorbidities class were more likely to use a computer to research health information, use a tablet or smartphone to track progress on a health-related goal, and watch health-related videos on YouTube-all types of self-management eHealth behaviors. These differences seemed to be largely driven by the combination of age and medical history as the 2 classes shared similar characteristics for other sociodemographic factors and medical experiences. However, those in the older with comorbidities and younger with no comorbidities classes showed no differences for other eHealth behaviors, such as (1) having health-related apps on their devices, (2) accessing health records for test results, (3) using electronic devices to treat a condition with clinicians, and (4) participating in a health-related support group. Collectively, these results demonstrate that although younger age and better health status jointly predict greater engagement in using eHealth for self-management, there is no generational divide in having health-related apps, accessing electronic health records, and sharing eHealth data with clinicians among cancer survivors with BMI in overweight or obese categories. Our results show agreement with mixed evidence that age is associated with eHealth use [34,35,37], and echo findings indicating that better health was associated with greater eHealth use to track health and goals [34,35].

The strengths of this study include the use of a large nationwide sample drawn from NCI HINTS which allowed us to use weightings to generate nationally representative estimates. Although the sample analyzed for the current study comprised less than $5 \%$ of the NCI HINTS study sample, the estimates are reflective of the population of cancer survivors with BMI in overweight or obese categories. Despite several eHealth weight management interventions in survivor populations, this is the first study to investigate how eHealth is used to manage health and relate to health care providers [50]. An additional strength was the ability to investigate different forms of eHealth usage separately, rather than in aggregate, which allowed us to identify who was more likely to use specific eHealth features to promote weight management and patient-clinician communication. A few limitations should be noted as well. We were unable to determine whether eHealth use would differ for diet, physical activity, or smoking behaviors since the NCI HINTS items did not distinguish between types of health-promoting behaviors. Another limitation is that eHealth use and cancer status were self-reported and, therefore, susceptible to recall bias. Although the data were weighted to generate nationally representative estimates, generalizability may still be limited by reliance on participant self-selection. Replication is warranted using different nationally representative study samples with further investigation on environmental factors, such as rural-urban differences [51]. Additionally, the temporal relationship between patient-related factors and eHealth use has yet to be established.

There is growing interest in the development and usability of eHealth to guide health-promoting behaviors for cancer survivors [52-54], particularly as there is limited access to nutrition services at cancer centers [9]. This study provides new evidence about the feasibility and usability of eHealth among cancer survivors with BMI in overweight or obese categories by investigating how sociodemographic factors, medical history, and medical experiences co-vary with eHealth behaviors. While our results suggest that all cancer survivors use eHealth, some groups engage with eHealth technologies in different ways. Thus, this study highlights the importance of considering the eHealth needs and usage patterns of different types of cancer survivors when developing digital interventions to support health promotion and patient-clinician communication. Our study also reveals that race/ethnicity, as well as medical attributes and experiences, predict eHealth use-lending support to the idea that sociodemographic, medical history, and clinician interactions can collectively influence eHealth engagement. 
Further efforts to develop eHealth recommendations tailored for different groups of cancer survivors are needed to optimize survivors' ability to use digital tools to promote health behaviors and reduce treatment-related morbidities and obesity.

\section{Acknowledgments}

AWL and SHB acknowledge salary support from National Institutes of Health/National Cancer Institute training grant T32 CA193193 (principal investigator: BS). NA is supported in part by National Institute of Diabetes and Digestive and Kidney Diseases K25DK113242 and National Science Foundation CNS1915847. BS is supported in part by National Institute of Diabetes and Digestive and Kidney Diseases R01s DK108678 and DK125414 and National Cancer Institute P30CA060553. Research reported in this publication was supported, in part, by the National Institutes of Health's National Center for Advancing Translational Sciences (grant number UL1TR001422). The content is solely the responsibility of the authors and does not necessarily represent the official views of the National Institutes of Health. The authors are grateful for the NCI HINTS investigators for their dedication in data collection and support. The authors would also like to thank the NCI HINTS participants for their contribution to research, as well as the reviewers and copyeditor (Coren Walters-Stewart) for their comments that have improved this manuscript.

\section{Conflicts of Interest}

None declared.

\section{Multimedia Appendix 1}

Latent class model based on patient-related factors of cancer survivors with BMI in overweight or obese categories. [DOCX File, 20 KB-Multimedia Appendix 1]

\section{References}

1. Miller KD, Nogueira L, Mariotto AB, Rowland JH, Yabroff KR, Alfano CM, et al. Cancer treatment and survivorship statistics, 2019. CA Cancer J Clin 2019 Sep 11;69(5):363-385 [FREE Full text] [doi: 10.3322/caac.21565] [Medline: 31184787]

2. Strongman H, Gadd S, Matthews A, Mansfield KE, Stanway S, Lyon AR, et al. Medium and long-term risks of specific cardiovascular diseases in survivors of 20 adult cancers: a population-based cohort study using multiple linked UK electronic health records databases. Lancet 2019 Sep 21;394(10203):1041-1054 [FREE Full text] [doi: 10.1016/S0140-6736(19)31674-5] [Medline: $\underline{31443926]}$

3. Curtis RE, Freedman DM, Ron E, Ries LAG, Hacker DG, Edwards BK, et al. New malignancies among people who have survived cancer NIH Publ. No 05-5302. SEER Cancer Registries, 1973-2000. Bethesda, MD: National Cancer Institute; 2006. URL: https://seer.cancer.gov/archive/publications/mpmono/MPMonograph complete.pdf

4. Søgaard M, Thomsen RW, Bossen KS, Sørensen HT, Nørgaard M. The impact of comorbidity on cancer survival: a review. Clin Epidemiol 2013 Nov 01;5(Suppl 1):3-29 [FREE Full text] [doi: 10.2147/CLEP.S47150] [Medline: 24227920]

5. Dietary Guidelines for Americans 2015-2020. Office of Disease Prevention and Health Promotion. 2015. URL: https:/ /health.gov/our-work/food-nutrition/2015-2020-dietary-guidelines/guidelines/ [accessed 2020-11-24]

6. Greenlee H, Shi Z, Sardo Molmenti CL, Rundle A, Tsai WY. Trends in Obesity Prevalence in Adults With a History of Cancer: Results From the US National Health Interview Survey, 1997 to 2014. J Clin Oncol 2016 Sep 10;34(26):3133-3140 [FREE Full text] [doi: 10.1200/JCO.2016.66.4391] [Medline: 27458295]

7. Pekmezi DW, Demark-Wahnefried W. Updated evidence in support of diet and exercise interventions in cancer survivors. Acta Oncol 2011 Feb;50(2):167-178 [FREE Full text] [doi: 10.3109/0284186X.2010.529822] [Medline: 21091401]

8. Stump TK, Robinson JK, Yanez B, Penedo F, Ezeofor A, Kircher S, et al. Physicians' perspectives on medication adherence and health promotion among cancer survivors. Cancer 2019 Dec 01;125(23):4319-4328. [doi: 10.1002/cncr.32410] [Medline: 31448414]

9. Trujillo EB, Claghorn K, Dixon SW, Hill EB, Braun A, Lipinski E, et al. Inadequate Nutrition Coverage in Outpatient Cancer Centers: Results of a National Survey. J Oncol 2019;2019:7462940 [FREE Full text] [doi: 10.1155/2019/7462940] [Medline: $\underline{31885583}$ ]

10. Mandracchia F, Llauradó E, Tarro L, Del Bas JM, Valls R, Pedret A, et al. Potential Use of Mobile Phone Applications for Self-Monitoring and Increasing Daily Fruit and Vegetable Consumption: A Systematized Review. Nutrients 2019 Mar 22;11(3):686 [FREE Full text] [doi: 10.3390/nu11030686] [Medline: 30909484]

11. Fawcett E, Van Velthoven MH, Meinert E. Long-Term Weight Management Using Wearable Technology in Overweight and Obese Adults: Systematic Review. JMIR Mhealth Uhealth 2020 Mar 10;8(3):e13461 [FREE Full text] [doi: 10.2196/13461] [Medline: $\underline{32154788]}$

12. Beleigoli AM, Andrade AQ, Cançado AG, Paulo MN, Diniz MDFH, Ribeiro AL. Web-Based Digital Health Interventions for Weight Loss and Lifestyle Habit Changes in Overweight and Obese Adults: Systematic Review and Meta-Analysis. J Med Internet Res 2019 Jan 08;21(1):e298 [FREE Full text] [doi: 10.2196/jmir.9609] [Medline: $\underline{\text { 30622090] }}$ 
13. Karduck J, Chapman-Novakofski K. Results of the Clinician Apps Survey, How Clinicians Working With Patients With Diabetes and Obesity Use Mobile Health Apps. J Nutr Educ Behav 2018 Jan;50(1):62-69.e1. [doi: 10.1016/j.jneb.2017.06.004] [Medline: 29325664]

14. Kirkovits T, Schinkoethe T, Drewes C, Gehring C, Bauerfeind I, Harbeck N, et al. eHealth in Modern Patient-Caregiver Communication: High Rate of Acceptance Among Physicians for Additional Support of Breast Cancer Patients During Long-Term Therapy. JMIR Cancer 2016 Sep 19;2(2):e14 [FREE Full text] [doi: 10.2196/cancer.5132] [Medline: 28410173]

15. Michie S, Richardson M, Johnston M, Abraham C, Francis J, Hardeman W, et al. The behavior change technique taxonomy (v1) of 93 hierarchically clustered techniques: building an international consensus for the reporting of behavior change interventions. Ann Behav Med 2013 Aug 20;46(1):81-95. [doi: 10.1007/s12160-013-9486-6] [Medline: 23512568]

16. Bantum EO, Albright CL, White KK, Berenberg JL, Layi G, Ritter PL, et al. Surviving and thriving with cancer using a Web-based health behavior change intervention: randomized controlled trial. J Med Internet Res 2014 Feb 24;16(2):e54 [FREE Full text] [doi: 10.2196/jmir.3020] [Medline: 24566820]

17. Forbes CC, Blanchard CM, Mummery WK, Courneya KS. Feasibility and Preliminary Efficacy of an Online Intervention to Increase Physical Activity in Nova Scotian Cancer Survivors: A Randomized Controlled Trial. JMIR Cancer 2015 Nov 23;1(2):e12 [FREE Full text] [doi: 10.2196/cancer.4586] [Medline: 28410166]

18. Kanera IM, Willems RA, Bolman CAW, Mesters I, Verboon P, Lechner L. Long-term effects of a web-based cancer aftercare intervention on moderate physical activity and vegetable consumption among early cancer survivors: a randomized controlled trial. Int J Behav Nutr Phys Act 2017 Feb 10;14(1):19 [FRE Full text] [doi: 10.1186/s12966-017-0474-2] [Medline: 28187725]

19. Lee MK, Yun YH, Park H, Lee ES, Jung KH, Noh D. A Web-based self-management exercise and diet intervention for breast cancer survivors: pilot randomized controlled trial. Int J Nurs Stud 2014 Dec;51(12):1557-1567. [doi: 10.1016/j.ijnurstu.2014.04.012] [Medline: 24856854]

20. Mayer DK, Landucci G, Awoyinka L, Atwood AK, Carmack CL, Demark-Wahnefried W, et al. SurvivorCHESS to increase physical activity in colon cancer survivors: can we get them moving? J Cancer Surviv 2018 Feb 9;12(1):82-94 [FREE Full text] [doi: 10.1007/s11764-017-0647-7] [Medline: 28994035]

21. Rabin C, Dunsiger S, Ness KK, Marcus BH. Internet-Based Physical Activity Intervention Targeting Young Adult Cancer Survivors. J Adolesc Young Adult Oncol 2011 Dec;1(4):188-194 [FREE Full text] [doi: 10.1089/jayao.2011.0040] [Medline: 23610737]

22. Ormel HL, van der Schoot GGF, Westerink NL, Sluiter WJ, Gietema JA, Walenkamp AME. Self-monitoring physical activity with a smartphone application in cancer patients: a randomized feasibility study (SMART-trial). Support Care Cancer 2018 Nov 21;26(11):3915-3923 [FREE Full text] [doi: 10.1007/s00520-018-4263-5] [Medline: 29785635]

23. Sajid S, Dale W, Mustian K, Kotwal A, Heckler C, Porto M, et al. Novel physical activity interventions for older patients with prostate cancer on hormone therapy: A pilot randomized study. J Geriatr Oncol 2016 Mar;7(2):71-80 [FREE Full text] [doi: 10.1016/j.jgo.2016.02.002] [Medline: 26916611]

24. Uhm KE, Yoo JS, Chung SH, Lee JD, Lee I, Kim JI, et al. Effects of exercise intervention in breast cancer patients: is mobile health (mHealth) with pedometer more effective than conventional program using brochure? Breast Cancer Res Treat 2017 Feb 8;161(3):443-452. [doi: 10.1007/s10549-016-4065-8] [Medline: 27933450]

25. Vallance JK, Courneya KS, Plotnikoff RC, Yasui Y, Mackey JR. Randomized Controlled Trial of the Effects of Print Materials and Step Pedometers on Physical Activity and Quality of Life in Breast Cancer Survivors. JCO 2007 Jun 10;25(17):2352-2359. [doi: 10.1200/jco.2006.07.9988]

26. Valle CG, Deal AM, Tate DF. Preventing weight gain in African American breast cancer survivors using smart scales and activity trackers: a randomized controlled pilot study. J Cancer Surviv 2017 Feb 8;11(1):133-148 [FREE Full text] [doi: 10.1007/s11764-016-0571-2] [Medline: 27631874]

27. Yun YH, Lee KS, Kim YW, Park SY, Lee ES, Noh DY, et al. Web-based tailored education program for disease-free cancer survivors with cancer-related fatigue: a randomized controlled trial. J Clin Oncol 2012 Apr 20;30(12):1296-1303. [doi: 10.1200/JCO.2011.37.2979] [Medline: 22412149]

28. Galiano-Castillo N, Arroyo-Morales M, Lozano-Lozano M, Fernández-Lao C, Martín-Martín L, Del-Moral-Ávila R, et al. Effect of an Internet-based telehealth system on functional capacity and cognition in breast cancer survivors: a secondary analysis of a randomized controlled trial. Support Care Cancer 2017 Nov 22;25(11):3551-3559. [doi: 10.1007/s00520-017-3782-9] [Medline: 28639097]

29. Krebs P, Shtaynberger J, McCabe M, Iocolano M, Williams K, Shuk E, et al. An eHealth Intervention to Increase Physical Activity and Healthy Eating in Older Adult Cancer Survivors: Summative Evaluation Results. JMIR Cancer 2017 Mar 01;3(1):e4 [FREE Full text] [doi: 10.2196/cancer.6435] [Medline: 28410171]

30. Kiss N, Baguley BJ, Ball K, Daly RM, Fraser SF, Granger CL, et al. Technology-Supported Self-Guided Nutrition and Physical Activity Interventions for Adults With Cancer: Systematic Review. JMIR Mhealth Uhealth 2019 Feb 12;7(2):e12281 [FREE Full text] [doi: 10.2196/12281] [Medline: $\underline{\text { 30747720] }}$

31. Roberts AL, Fisher A, Smith L, Heinrich M, Potts HWW. Digital health behaviour change interventions targeting physical activity and diet in cancer survivors: a systematic review and meta-analysis. J Cancer Surviv 2017 Dec 4;11(6):704-719 [FREE Full text] [doi: 10.1007/s11764-017-0632-1] [Medline: 28779220] 
32. Guidry JJ, Torrence W, Herbelin S. Closing the divide: diverse populations and cancer survivorship. Cancer 2005 Dec 01;104(11 Suppl):2577-2583 [FREE Full text] [doi: 10.1002/cncr.21251] [Medline: 16258930]

33. Robinson L, Cotten SR, Ono H, Quan-Haase A, Mesch G, Chen W, et al. Digital inequalities and why they matter. Information, Communication \& Society 2015 Mar 16;18(5):569-582. [doi: 10.1080/1369118x.2015.1012532]

34. Rising CJ, Jensen RE, Moser RP, Oh A. Characterizing the US Population by Patterns of Mobile Health Use for Health and Behavioral Tracking: Analysis of the National Cancer Institute's Health Information National Trends Survey Data. J Med Internet Res 2020 May 14;22(5):e16299 [FREE Full text] [doi: 10.2196/16299] [Medline: 32406865]

35. Paré G, Leaver C, Bourget C. Diffusion of the Digital Health Self-Tracking Movement in Canada: Results of a National Survey. J Med Internet Res 2018 May 02;20(5):e177 [FREE Full text] [doi: 10.2196/jmir.9388] [Medline: 29720359]

36. Mahmood A, Kedia S, Wyant DK, Ahn S, Bhuyan SS. Use of mobile health applications for health-promoting behavior among individuals with chronic medical conditions. Digit Health 2019 Oct 10;5:2055207619882181 [FREE Full text] [doi: 10.1177/2055207619882181] [Medline: 31656632]

37. Nouri SS, Adler-Milstein J, Thao C, Acharya P, Barr-Walker J, Sarkar U, et al. Patient characteristics associated with objective measures of digital health tool use in the United States: A literature review. J Am Med Inform Assoc 2020 May 01;27(5):834-841. [doi: 10.1093/jamia/ocaa024] [Medline: $\underline{32364238]}$

38. Senft N, Everson J. eHealth Engagement as a Response to Negative Healthcare Experiences: Cross-Sectional Survey Analysis. J Med Internet Res 2018 Dec 05;20(12):e11034 [FREE Full text] [doi: 10.2196/11034] [Medline: 30518513]

39. Halpern MT, McCabe MS, Burg MA. The Cancer Survivorship Journey: Models of Care, Disparities, Barriers, and Future Directions. Am Soc Clin Oncol Educ Book 2016;35:231-239 [FREE Full text] [doi: 10.1200/EDBK_156039] [Medline: 27249703]

40. Defining adult overweight and obesity. Centers for Disease Control and Prevention. URL: https://www.cdc.gov/obesity/ adult/defining.html [accessed 2020-11-17]

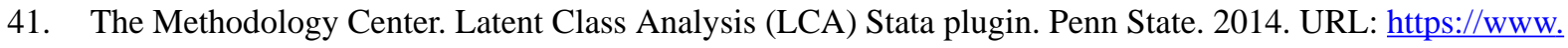
methodology.psu.edu/downloads/lcastata/ [accessed 2019-10-01]

42. Muthen B, Asparouhov T. Item response mixture modeling: application to tobacco dependence criteria. Addict Behav 2006 Jun;31(6):1050-1066. [doi: 10.1016/j.addbeh.2006.03.026] [Medline: 16675147]

43. Nylund KL, Asparouhov T, Muthén BO. Deciding on the Number of Classes in Latent Class Analysis and Growth Mixture Modeling: A Monte Carlo Simulation Study. Structural Equation Modeling: A Multidisciplinary Journal 2007 Dec 05;14(4):535-569. [doi: 10.1080/10705510701575396]

44. Masyn K, Little TD. Latent class analysis finite mixture modeling. In: The Oxford Handbook of Quantitative Methods: Statistical Analysis. Oxford, England: Oxford University Press; 2013:551-611.

45. Clark SL, Muthén B. Relating latent class analysis results to variables not included in the analysis. 2009 Apr 22. URL: https://www.statmodel.com/papers.shtml [accessed 2020-04-22]

46. Parente ST, Van Horn RL. Valuing hospital investment in information technology: does governance make a difference? Health Care Financ Rev 2006;28(2):31-43 [FREE Full text] [Medline: 17427843]

47. Palmer NR, Geiger AM, Felder TM, Lu L, Case LD, Weaver KE. Racial/Ethnic disparities in health care receipt among male cancer survivors. Am J Public Health 2013 Jul;103(7):1306-1313 [FREE Full text] [doi: 10.2105/AJPH.2012.301096] [Medline: 23678936]

48. Kenzik K, Pisu M, Fouad MN, Martin MY. Are long-term cancer survivors and physicians discussing health promotion and healthy behaviors? J Cancer Surviv 2016 Apr 26;10(2):271-279 [FREE Full text] [doi: 10.1007/s11764-015-0473-8] [Medline: 26210659]

49. National health care quality and disparities report Pub No. 19-0070-EF. Agency for Health Care Research Quality. Rockville, MD: AHRQ; 2019. URL: https://www.ahrq.gov/research/findings/nhqrdr/index.html [accessed 2020-11-24]

50. Quintiliani LM, Mann DM, Puputti M, Quinn E, Bowen DJ. Pilot and Feasibility Test of a Mobile Health-Supported Behavioral Counseling Intervention for Weight Management Among Breast Cancer Survivors. JMIR Cancer 2016 May 09;2(1):e4 [FREE Full text] [doi: 10.2196/cancer.5305] [Medline: 28410174]

51. Chen X, Orom H, Hay JL, Waters EA, Schofield E, Li Y, et al. Differences in Rural and Urban Health Information Access and Use. J Rural Health 2019 Jun 16;35(3):405-417 [FREE Full text] [doi: 10.1111/jrh.12335] [Medline: 30444935]

52. O'Malley DM, Davis SN, Devine KA, Sullivan B, Bator A, Clemow L, et al. Development and usability testing of the e-EXCELS tool to guide cancer survivorship follow-up care. Psychooncology 2020 Jan 18;29(1):123-131 [FREE Full text] [doi: 10.1002/pon.5222] [Medline: 31626397]

53. Leach CR, Diefenbach MA, Fleszar S, Alfano CM, Stephens RL, Riehman K, et al. A user centered design approach to development of an online self-management program for cancer survivors: Springboard Beyond Cancer. Psychooncology 2019 Oct 14;28(10):2060-2067. [doi: 10.1002/pon.5193] [Medline: 31379069]

54. Coughlin SS, Besenyi GM, Bowen D, De Leo G. Development of the Physical activity and Your Nutrition for Cancer (PYNC) smartphone app for preventing breast cancer in women. Mhealth 2017 Feb 15;3:5-5 [FREE Full text] [doi: 10.21037/mhealth.2017.02.02] [Medline: 28293621] 


\section{Abbreviations}

AIC: Akaike information criterion

BIC: Bayesian information criterion

NCI HINTS: National Cancer Institute Health Information National Trends Survey

OR: odds ratio

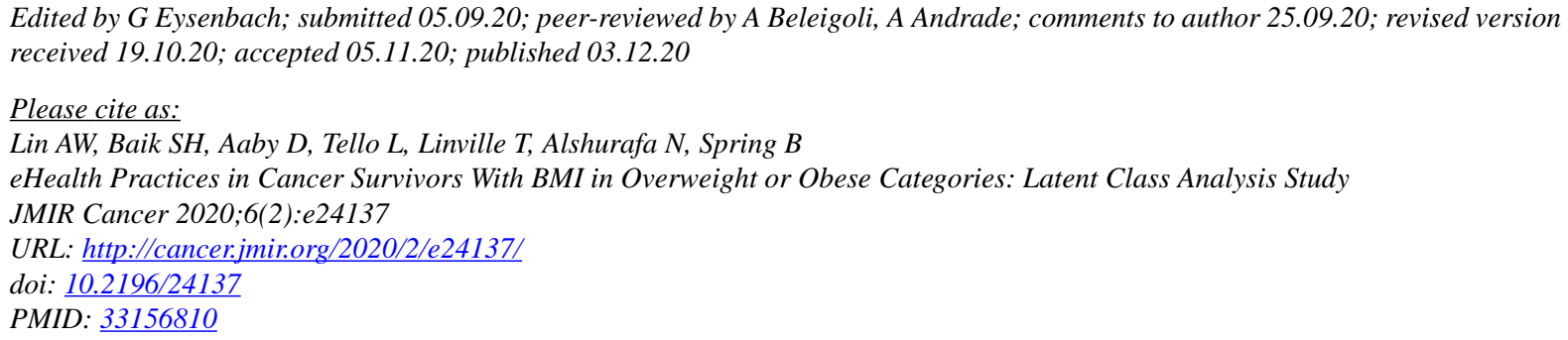

(C)Annie Wen Lin, Sharon H Baik, David Aaby, Leslie Tello, Twila Linville, Nabil Alshurafa, Bonnie Spring. Originally published in JMIR Cancer (http://cancer.jmir.org), 03.12.2020. This is an open-access article distributed under the terms of the Creative Commons Attribution License (https://creativecommons.org/licenses/by/4.0/), which permits unrestricted use, distribution, and reproduction in any medium, provided the original work, first published in JMIR Cancer, is properly cited. The complete bibliographic information, a link to the original publication on http://cancer.jmir.org/, as well as this copyright and license information must be included. 